\title{
ICT Based Screening Tools and Etiology of Dyscalculia
}

\author{
http://dx.doi.org/10.3991/ijep.v5i3.4735 \\ Marios A. Pappas, Athanasios S. Drigas \\ NCSR DEMOKRITOS, Institute of Informatics and Telecommunications, Net Media Lab, Athens, Greece
}

\begin{abstract}
Developmental Dyscalculia (DD) is a specific learning disability of childhood, which is mainly related to problems in arithmetic skills and numerosity. It is estimated that the prevalence of dyscalculia range between 3 and $6 \%$ of the world population. DD is a cognitive disorder, observed during the development of the individual. Mathematical achievement of children with DD fall far short of their mental capacity. In this study we present an approach to genetic, neurological and environmental factors associated with DD, as well as the computerized screening tools that have been developed and used so far, according to the literature review of the past two decades.
\end{abstract}

Index Terms-ICT based Screening, Developmental Dyscalculia, Diagnostic Tools, Etiology.

\section{INTRODUCTION}

Dyscalculia is a term from the greek $d y s$ and the latin calculia. There are several different terms to describe the mathematic learning disabilities. Many researchers and educators use the term Mathematics Learning Disability (MLS), while Ladislav Kosc (1974) a Czechoslovakian psychologist introduced the term Developmental Dyscalculia . Koontz and Berch (1996) used the term Arithmetic Learning Disabilities. Hich prefers the term Specific Arithmetic Difficulties, while Temple and Sherwood (2002) use the term Number fact Disorder (Butterworth, 2008).

Dyscalculia, as the name implies, is a disorder associated with the numerical skills. There is a distinction between the terms developmental dyscalculia and acquired dyscalculia. The first term refers to persons in school age who come into contact with mathematical knowledge and skills for the first time, while the second relates to people who have learned mathematics but later in childhood or more often in adulthood lose this ability, because of some acquired disorder associated with brain damage. We could use the term DD to describe students who have significant problems with numbers while having normal intelligence. Even though dyscalculics' difficulties are not confined to mathematics, as they face difficulties in daily problems, handling or telling the time, orientation, counting money, and much more, their feature is the inability to perceive numbers as quantities and process mathematical concepts (Pearl, 2010). For most children it seems obvious that when they see two numbers they can understand if they are the same or not and which of them is greater. This does not apply to children with DD, as they have difficulties relative to the intuitive perception of the numbers as quantities (Price and Ansari, 2013). Furthermore, children with dyscalculia may have difficulty in measuring objects or to countdown and to estimate approximately a collec- tion of objects. Landerl, Bevan and Butterworth (2004) examined dyscalculics' basic numerical processing in detail and proposed a subtyping of the deficits into number reading and naming, number comparison, number writing, number sequences and dot counting. In addition, children with DD face difficulties in learning musical concepts, follow instructions in sports that require a logical a series of acts and difficulty to keep the score and the number of players in board games and cards. There is a clear association between the approximate number system, better known as number sense and developmental dyscalculia (Piazza, 2010). Persons with DD have also difficulties in the automatic activation of magnitudes by digits.

Dyscalculia has a high comorbidity with other learning disabilities such as dyslexia, ADHD and dyspraxia. We can describe the heterogenous nature of DD as consequence of different impairments, including working memory and attention deficits (Fias, Menon \& Szucs, 2013).The purpose of this study is to investigate the causes that are possibly related to developmental dyscalculia. Based on the current literature, we present neurological disorders, brain differences and genetic features of children with DD, as well as the role of working memory and math anxiety in arithmetic skills. In addition we present some computerized tools which have been developed to assess numerical achievement, as well as to measure working memory, attention and cognitive skills.

\section{NEYROPSYCHOLOGICAL APPROACH}

One of the factors that significantly affect mathematical performance is arguably the neuropsychological basis of mathematical knowledge. The left cerebral hemisphere in the context of mathematics is responsible for counting, recognition of the symbols of numbers and operations, to hold a series of numerical data on the implementation of the algorithm of operations for logical analysis and generally for arithmetic skills. Faults and malfunctions of the left hemisphere may result changes in execution of operations, difficulties in retention and recall of key figures and problems in understanding the concept of numbers.

In recent years researchers of two parts, Neuroscience and Education, recognize the connection between the two sciences and the need of cooperation and conducting research efforts jointly. Recent studies indicate that the cause of dyscalculia ought to dysfunction of brain regions. Neuroimaging studies established the intraperital sulcus (IPS) as the critical area for processing numbers and comparison of digits (Butterworth and Laurillard, 2010). In an attempt to understand the developmental disorders in order to design appropriate intervention programs, it is required the development of brain-based theories. The last decade began a systematic investigation of the neurologi- 
cal factors of DD. Very little is known about the biological origins of DD and the biological origins of brain dysfunctions (Rubisten, 2009).

Finger gnosis, finger recognition and finger discrimination appear to be directly related to calculation skills. Specific areas of the brain are activated when children use their fingers in their attempt to comprehend an arithmetic problem, as the use of fingers could affect the formation of mental number representation. So it seems that educators could benefit from this fact and they should encourage dyscalculic children to use their fingers in arithmetic (Kauffman).

Mussolin et al (2001) analyzed the cerebral bases of DD related to symbolic number processing. In their study participated 15 children with DD and 15 control children without learning disabilities, who were investigated via functional magnetic resonance imaging (fMRI). The brain analysis revealed that control children showed greater activation than children with DD in and around the IPS bilaterally. Dyscalculia is associated with impairment in areas involved in number magnitude processing, as well as in areas dedicated to domain general magnitude prossecing.

Rotzer et al (2007) used optimized voxel-based morphometry (OVBM) to evaluate 12 dyscalculic 9-year old children and 12 control children without learning disabilities. Children with DD showed decreased grey matter volume in the right intraparietal sulcus (IPS) in relation to controls, while the left IPS showed no volume differences. They also showed decreased white matter volume of the right parahippocampal gyrus, which affects fact retrieval and spatial memory processes.

In 2009 Rykhlevskaia et al investigated the neuroanatomical correlates of DD. Forty seven 7-9 year old children participated in their study. Twenty three children consisted the dyscalculic group, based on their scores on 2 subscales of the Wechler Individual Achievement Test (WIAT-II), Numerical Operations Score and Math Composite Score, and 24 children formed the control group. All the participants had scored normally on standardized measures of IQ, reading and working memory. Researchers used structural MRI and DTI (Diffusion Tensor Imaging) to examine macro and micro-structural impairments on the participants. The results revealed that Grey Matter and White Matter deficits in specific brain areas are directly involved in mathematical cognition. Children with DD showed decreased GM volume in several posterior regions compared to non-dyscalculic. As well children with DD decreased WM volume in the posterior brain and mainly next to the temporal parietal cortex (Figure 1).

In the same year Kauffman et al investigated the neural correlates of non-symbolic number magnitude processing in 9 year old children with and without dyscalculia. Children with dyscalculia showed a deficit in numerosity and were slower in making number magnitude classifications than children in control group. Results revealed significant (intra)parietal activation differences between children with and without dyscalculia. There were reported stronger activations in left (intra)parietal regions in dycalculic children relative to children in control group.

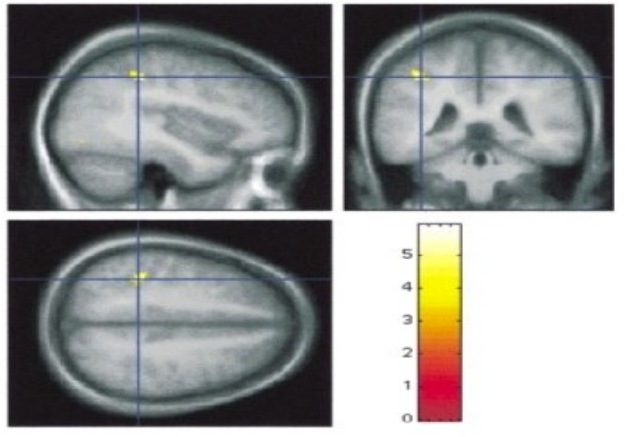

Figure 1. Less Grey Matter in dyscalculic children (Isaacs et al, 2001)

\section{GENETIC BASIS}

As the studies of last decades have shown, Developmental Dyscalculia is a neurocognitive disorder with a genetic base, which is largely familiar. In a study with 39 children with DD, Shalev (2001) found that $66 \%$ of mothers, $40 \%$ of mothers, $53 \%$ of siblings and $44 \%$ of seconddegree relatives had also DD.

It could be considered that a single brain malfunction, for example a dysfunction of the fusiform gyrus or the IPS, could result multiple cognitive or behavioral disorders. Many children have dyslexia or attention- deficit/hyperactivity disorder (ADHD) in parallel with DD (Rubinsten and Henik, 2009). It is estimated that the $40 \%$ of children with dyslexia also have math disability. Dysgraphia, finger agnosia, Attention-Deficit Hyperactivity Disorder and difficulties with left right discrimination have also been associated with dyscalculia. However according to Monuteaux et al (2005) ADHD and DD have no common etiological basis and therefore is required the development of individual assessment and interaction strategies. Children with Williams syndrome as well as with Turner syndrome present particular difficulties in arithmetic skills as counting, remembering arithmetic facts and simple calculations (Butterworth).

Review of the literature does not allow to draw firm conclusions for the gender ratio of DD. In 2013 Devine et al tested 1004 primary school children in England. Both boys and girls achieved similar scores in Mathematics Assessment for Learning and Teaching tests (MaLT). Dirks et al (2008) who assessed 799 Dutch schoolchildren via standardized school arithmetic achievement tests, reported that the prevalence of DD was slightly higher for girls than boys. In addition Jovanovic et al developed a study (2013) with 1424 third grade students in Serbia, which revealed that among 107 students with low arithmetic achievement, there were 70 boys and 38 girls.

\section{$I V$. WORKING MEMORY DeFICITS}

Working memory is responsible for the temporary processing and storage of information. It consists of a central executive which controls the activities of all the other components and two subsystems, phonological loop and visuospatial sketchpad (Figure 2), which are responsible for the storage of verbal and visual/spatial information respectively (Rosselli, 2006). Working memory has limited capacity and is involved with the maintenance of recent edited information and its connection with the latest input (Swanson and Frankenberger, 2004). In 2009 Noel measured how much limited working memory capacity affects early numerical development in 4-5 year old chil- 
dren. According to the results, performance in additions and counting skills was significantly correlated with central executive capacity but not with phonological loop or visuo-spatial sketchpad capacity. Working memory could be defined as to focus on a problem and to perform the required functions, utilizing the data, in order to reach the solution (Beilock and Carr, 2005).

Research has shown that there is significant correlation between the components of the working memory and mathematics attainment (Holmes and Adams, 2006). Children with DD display working memory deficit compared to normally achieving children, therefore they face difficulties both in simple arithmetic calculations and to develop strategies to solve complex problems. To investigate the relationship of working memory to implement of arithmetic operations, it is important to consider the role of counting span. During an arithmetic operation, children have to maintain one or more numbers while engaged in the process of calculation. Counting span is the number of digits that can be stored in working memory (Geary). Passolunghi et al (2004) claimed that computation and arithmetic word problem ability could be improved if the accessibility of the working memory of useless information was reduced.

Szucs et al (2013) examined the ration between visuospatial memory and DD. One hundred ten children, who were defined to have dyscalculia via the standardized Mathematics Assessment and Teaching test (MaLT) and WIAT-II numerical subtests, were administered five subtests of the Automated Working Memory Assessment (AWMA), a PC-based assessment of working memory (WM) and short-term memory (STM) skills:

- Digit Span (verbal STM)

- Word Recall (verbal STM)

- Dot Matrix (visuo-spatial STM)

- Listening Span (verbal WM)

- Odd One Out (visuo-spatial WM)

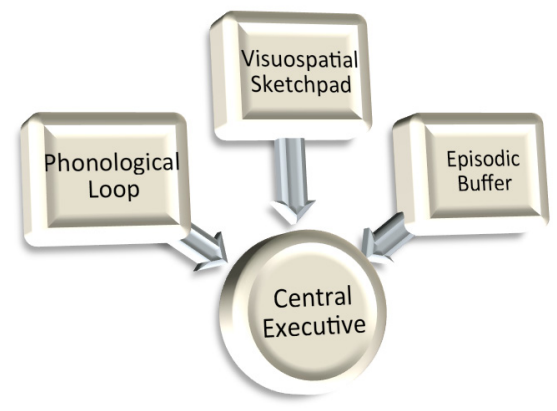

Figure 2. Working Memory

\section{A. Attention Deficits}

It seems that the comorbidity of DD and ADHD is larger than comorbidity with other learning disabilities (Anshkenazi, 2009). Many studies have focuced on the correlation of DD and ADHD, as well as on the attention deficits of dyscalculic children without ADHD. The correlation between attention and achievement in mathematics extends to ages later than preschool, namely from 8 to 11 years. (Anobile, Sievano and Burr, 2013).

Rubinsten and Henik (2005) examined dyscalculic children using numerical Stroop task and found that the ability to efficiently process the quantities associated with
Arabic numbers is less developed in dyscalculic children than those without learning disabilities. In Stroop tasks, a multi dimensional objects is presented on a computer screen and children have to attend to one dimension while ignoring other dimensions. The results showed that children with DD have problems in automatic activation of magnitudes of digits.

Askenazi and Henik (2010) examined the attention abilities in developmental dyscalculia using the Attention Network Task (ANT-I), a computer based reaction time task that measures executive function with avariation of the flanker task. Participants had to attend to one object and ignore all the other objects. In each trial, five arrows were presented on the screen. Participants had to attend to the arrow in the middle and choose if it was pointing to the left or to the right. The results revealed deficits in the executive function and the alertness networks in children diagnosed as having DD.

Guarnera and D'Amico (2014) examined if training of basic attentive skills could improve working memory abilities in children with dyscalculia. To evaluate the attentional abilities researchers used Attenzione e Concentranzione, a computerized assessment battery of 7 tasks: Simple Reaction Time, Speed and Accuracy, Auditory and Visual Recognition, Digit Span, Divided Attention, Colour Word Interfence Task and Attentive Shifting to assess simple reaction time, visual-spatial and auditory skills, digit span, divided attention, distraction and attentive shifting. According to the results there is need for planning individualized training programs as there was no effect on dyscalculics' WM.

In 2007 Willburger et al evaluated the rapid naming speed in children with dyslexia and children with DD. Rapid naming speed is the ability to name sequentially presented letters, digits or pictured objects as quickly as possible. Except from the standardized reading and arithmetic tasks, researchers also used three subtests of KITAP (Zimmermann et al, 2002), a computerized battery, to assess processing speed and reaction time and three standard Rapid Automatized Naming (RAN) tasks from a Dutch computerized battery. Dyscalculic children showed a domain-specific deficit in rapid naming of quantities.

\section{MATH ANXIETY}

Math anxiety is a negative emotional reaction of the person in circumstances which require understanding and applying mathematical operations to solve problems. People who suffer from math anxiety feel unable to participate in activities and lessons that contain maths. Students with high levels of math anxiety get poorer grades in the math classes, have reduced confidence in their ability on mathematics and may be less likely to attend math courses or math-related careers (Scarpello, 2007). It is considered that math anxiety mainly grows in junior high school when the math curriculum complicates considerably. When performing mathematical calculation, children with high levels of math anxiety develop negative emotions. Therefore underlines the role of the emotional factor in situations that require mathematical thinking (Maloney and Beilock, 2012). Several factors in the class could increase students' math anxiety as when a student is called to the board to solve a problem or a non-supportive teacher (Ashcraft and Krause, 2007). Many teachers, mainly in primary education, have math anxiety themselves and transmit it unwittingly on children (Geist, 2010). 
Children with DD may have higher levels of math anxiety than non-dyscalculic children. In $2014 \mathrm{Wu}$ et al assessed 366 children (average age 8.27 years) using the Scale for Early Mathematics Anxiety (SEMA). The results revealed that math anxiety is remarkably correlated with math achievement, concluding that poor achievement in mathematics is not simply the result of high levels of trait anxiety. Krinzinger et al (2009) investigating the link between math anxiety and math performance in early school years concluded that only in cases of extremely high levels of math anxiety it could have a negative effect on math performance. Woodard (2004) suggests that educators need to recognize the causes of math anxiety, such as poor math instruction, negative attitudes about mathematics courses, negative math experiences, and low selfesteem and implement individualized teaching approach to students who face such a problem.

\section{COMPUTERISED SCREENING TOOLS FOR DEVELOPMENTAL DYSCALCULIA.}

Computerized screening tools are reported to be the new trend in diagnosis and assessment of learning disabilities. Although there are several paper and pencil screening tools for dyscalculia and arithmetic achievement, Number Sets Test (Geary, 2009), TEDI-MATH (Gregoire, Noel \& Van Nieuwenhoven, 2004), Heidelberger Rechentest (HRT: Haffner, Baro, Parzer \& Resch, 2005), MaLT (Williams,2005), Number Knowledge Test (NKT: Okamoto \& Case, 1996), TTR (De Vos, 1992), Kortrijk Arithmetic Test Revision (KRT-R, Baudonck et al, 2006), Number Sense Brief (NSB: Jordan, Glutting, Raminem \& Watkins, 2010), Test of Early Mathematics Achievement (TEMA: Ginsbury \& Baroody, 2003) etc, there have been developed only a few computerized screening tools.

Based on the neuropsycological correlates of DD, Cangoz et al (2013) proposed a computer based screening DD test for 6-9 year old children. The screener's tasks consists of dot counting, number comparison, perceptual quantity estimation, number line estimation and simple arithmetic. Researchers designed the screening tool to be compatible with Android tablets, as due to their portability, they are easily accessible in the classroom and despite that they are very popular to children.

Plerou. Vlamos and Kourouthanasis (2014) proposed a computer based diagnostic screener referring to dyscalculia and algorithmic thinking difficulties. They integrated into the screener animation technology including bitmap, images, audio, native 3D rendering, text, hypertext and video. The screener was designed to assess difficulties in number visual perception and problems in spatial conception via interaction activities through visual representations. Digital Screener test controls five key areas:

- Problems in visual perception of numbers

- Troubles in spatial concepts and geometry.

- Difficulties in calculating.

- Difficulties in perception of time.

- Difficulties in algorithmic thinking.

Trott and Beacham at Loughborough University, developed Dyscalculium, a first-line screening tool for dyscalculia. This online screener examines the understanding of number concepts and quantitative comparisons to identify students at risk of dyscalculia. Students complete online the Dyscalculium portal without time limit and after that the results are automatically analyzed, proving individual profile for each student. The screening tool is based on six categories about understanding of numbers:

- Operational (conceptual and inferential)

- Number Comparative (visual-spatial, word and symbolic)

- Number Conceptual

- and five categories of everyday applications:

- Graphical (tabular and graphical)

- Spatial Temporal (direction and time)

- Symbolic Abstraction

Butterworth (2003) developed Dyscalculia Screener, a computer based standardized test, designed to diagnose dyscalculia in children from 6 to 14 years old. The screener consists of four computer-controlled tests:

- Simple Reaction Time

- Dot Enumeration

- Number Comparison

- Arithmetic Achievement Test (addition and multiplication)

The duration of the test ranges from 15 to 30 minutes. According to Butterworth, Dyscalculia Screener is not a general test of mathematical achievement, as it is focused on diagnosis of dyscalculia.

In a study with 11,652 participants from second to ninth grades (average age 10,86 years), Crespo et al (2012) used the $B N B$ PC-based assessment to identify children with basic numerical deficits, developmental dyscalculia (DD) and arithmetic dysfluency (AD). Basic Numerical Battery $(B N B)$ is a battery of item-timed computerized tests. The battery consists of two numerical capacity tests, dot enumeration in which children were asked to enumerate the quantities of dots presented on the computer screen, and numerical magnitude where children had to compare the magnitude of two digits (1-9), and a test of mental arithmetic fluency with 15 additions, 15 subtractions and 15 multiplications. The number of correct responses as well as the time reaction were measured as criteria for classifying children. The results of the study showed that capacity tests of BNB are precise and predictive tools for identifying DD.

In 2012, Manghirmalani, More and Jain proposed an alternative approach to classify learning disability. The reasoning of this soft computing technique called Fuzzy Expert System is similar to human reasoning. This allows to reach firm conclusions from incomplete or unclear data. A curriculum-based test with 11 input parameters (Essay, Reading, Comprehension, Spelling, Perception, Solve, Word Problem, Mental Sums, Time, Calander and Money) was designed for collecting learning disability datasets. The proposed model assists in the diagnosis and classification of learning disability that is dyslexia, dysgraphia or dyscalculia, with an accuracy of about $90 \%$.

\section{CONCLUSIONS}

The diagnosis of developmental dyscalculia is not a simple task, given the diversity of symptoms and possible causes of the disorder. During the last decade mainly, there have been some attempts to design computerized screening tools for dyscalculia, although further investigation is required with regard to the development and balancing of the tools in order to allow a massive utilization. 


\section{REFERENCES}

[1] Anobile, G., Stievano, P., \& Burr, D. C. (2013). Visual sustained attention and numerosity sensitivity correlate with math achievement in children. Journal of experimental child psychology, 116(2), 380-391. http://dx.doi.org/10.1016/j.jecp.2013.06.006

[2] Antonia, P., Panagiotis, V., \& Panagiotis, K. Screening Dyscalculia and Algorithmic Thinking Difficulties "1st International Conference on New Developments in Science and Technology Education" Proceedings Manuscripts.

[3] Ashcraft, M. H., \& Krause, J. A. (2007). Working memory, math performance, and math anxiety. Psychonomic bulletin \& review, 14(2), 243-248. http://dx.doi.org/10.3758/BF03194059

[4] Ashkenazi, S., Rubinsten, O., \& Henik, A. (2009). Attention, automaticity, and developmental dyscalculia. Neuropsychology, 23(4), 535. http://psycnet.apa.org/doi/10.1037/a0015347

[5] Askenazi, S., \& Henik, A. (2010). Attentional networks in developmental dyscalculia. Behavioral and brain functions, 6(2), 1-12.

[6] Baudonck, M., Debusschere, A., Dewulf, B., Samyn, F., Vercaemst, V., \& Desoete, A. (2006). De Kortrijkse Rekentest Revision KRT-R.[The Kortrijk Arithmetic Test Revision KRT-R]. Kortrijk: CAR Overleie.

[7] Beacham, N., \& Trott, C. Developing a screening tool for dyscalculia. In CETL-MSOR Conference 2006 (p. 14).

[8] Beilock, S. L., \& Carr, T. H. (2005). When high-powered people fail working memory and "choking under pressure" in math. Psychological Science, 16(2), 101-105. http://dx.doi.org/10.1111/j.09567976.2005.00789.x

[9] Bliss, S. (2006). Test Reviews: Ginsburg, H., \& Baroody, A.(2003)." Test of Early Mathematics Ability--" Austin, TX: ProEd. Journal of psychoeducational Assessment, 24(1), 85-98.

[10] Butterworth, B. (2003). Dyscalculia screener. nferNelson Publishing Company Limited, London.

[11] Butterworth, B. (2008). Developmental dyscalculia. Child neuropsychology: Concepts, theory, and practice, 357-374.

[12] Butterworth, B., \& Laurillard, D. (2010). Low numeracy and dyscalculia: identification and intervention. ZDM, 42(6), 527-539. http://dx.doi.org/10.1126/science.1201536

[13] Cangoz, B., Altun, A., Olkun, S., \& Kacar, F. (2013). Computer Based Screening Dyscalculia: Cognitive and Neuropsychological Correlates. Turkish Online Journal of Educational TechnologyTOJET, 12(3), 33-38.

[14] De Vos, T. (1992). TTR. Tempotest rekenen [Arithmetic number fact test].

[15] Devine, A., Soltész, F., Nobes, A., Goswami, U., \& Szücs, D. (2013). Gender differences in developmental dyscalculia depend on diagnostic criteria.Learning and Instruction, 27, 31-39. http://dx.doi.org/10.1016/j.learninstruc.2013.02.004

[16] Dirks, E., Spyer, G., van Lieshout, E. C., \& de Sonneville, L. (2008). Prevalence of combined reading and arithmetic disabilities. Journal of Learning Disabilities, 41(5), 460-473. http://dx.doi.org/10.1177/0022219408321128

[17] Fias, W., Menon, V., \& Szucs, D. (2013). Multiple components of developmental dyscalculia. Trends in Neuroscience and Education, 2(2), 43-47. http://dx.doi.org/10.1016/j.tine.2013.06.006

[18] Geary, D. C., Bailey, D. H., \& Hoard, M. K. (2009). Predicting mathematical achievement and mathematical learning disability with a simple screening tool the number sets test. Journal of Psychoeducational Assessment, 27(3), 265-279. http://dx.doi.org/10.1177/0734282908330592

[19] Geary, D. C., Hoard, M. K., Byrd-Craven, J., \& DeSoto, M. C. (2004). Strategy choices in simple and complex addition: Contributions of working memory and counting knowledge for children with mathematical disability. Journal of experimental child psychology, $88(2), \quad 121-151$. http://dx.doi.org/10.1016/j.jecp.2004.03.002

[20] Geist, E. (2010). The anti-anxiety curriculum: Combating math anxiety in the classroom. Journal of Instructional Psychology, $37(1), 24$

[21] Grégoire, J., Van Nieuwenhoven, C., \& Noël, M. (2004). TEDIMATH (Flemish adaptation: A. Desoete, H. Roeyers, \& M. Schittekatte). Brussels: TeMA.
[22] Guarnera, M., \& D'Amico, A. (2014). Training of Attention in Children With Low Arithmetical Achievement. Europe's Journal of Psychology, 10(2), 277-290. http://dx.doi.org/10.5964/ejop.v10i2.744

[23] Haffner, J., Baro, K., Parzer, P., \& Resch, F. (2005). Heidelberger Rechentest (HRT) Hogrefe. Göttingen, Germany.

[24] Holmes, J., \& Adams, J. W. (2006). Working memory and children's mathematical skills: Implications for mathematical development and mathematics curricula. Educational Psychology, 26(3), 339-366. http://dx.doi.org/10.1080/87565640801982312

[25] Isaacs, E. B., Edmonds, C. J., Lucas, A., \& Gadian, D. G. (2001). Calculation difficulties in children of very low birthweight. Brain, 124(9), 1701-1707. http://dx.doi.org/10.1093/brain/124.9.1701

[26] Jordan, N. C., Glutting, J., \& Ramineni, C. (2010). The importance of number sense to mathematics achievement in first and third grades. Learning and individual differences, 20(2), 82-88. http://dx.doi.org/10.1016/j.lindif.2009.07.004

[27] Jovanović, G., Jovanović, Z., Banković-Gajić, J., Nikolić, A., Svetozarević, S., \& Ignjatović-Ristić, D. (2013). The frequency of dyscalculia among primary school children. Psychiatria Danubina, 25(2), 170-174.

[28] Kaufmann, L. (2008). Dyscalculia: neuroscience and education. Educational $\quad$ Research, 163-175. http://dx.doi.org/10.1080/00131880802082658

[29] Kaufmann, L., Vogel, S. E., Starke, M., Kremser, C., Schocke, M., \& Wood, G. (2009). Developmental dyscalculia: compensatory mechanisms in left intraparietal regions in response to nonsymbolic magnitudes. Behavioral and Brain Functions, 5(1), 35. http://dx.doi.org/doi:10.1186/1744-9081-5-35

[30] Krinzinger, H., Kaufmann, L., \& Willmes, K. (2009). Math anxiety and math ability in early primary school years. Journal of psychoeducational assessment, 27(3), 206-225. http://dx.doi.org/10.1177/0734282908330583

[31] Landerl, K., Bevan, A., \& Butterworth, B. (2004). Developmental dyscalculia and basic numerical capacities: A study of 8-9-yearold students. Cognition,93(2), 99-125. http://dx.doi.org/10.1016/j.cognition.2003.11.004

[32] Maloney, E. A., \& Beilock, S. L. (2012). Math anxiety: Who has it, why it develops, and how to guard against it. Trends in cognitive sciences, 16(8), 404-406. http://dx.doi.org/10.1016/j.tics.2012.06.008

[33] Manghirmalani, P., More, D., \& Jain, K. (2012). A Fuzzy Approach To Classify Learning Disability, (IJARAI) International Journal of Advanced Research in Artificial Intelligence, 1(2), pp.1-7.

[34] Monuteaux, M. C., Faraone, S. V., Herzig, K., Navsaria, N., \& Biederman, J. (2005). ADHD and dyscalculia evidence for independent familial transmission.Journal of learning disabilities, 38(1), 86-93. http://dx.doi.org/10.1177/00222194050380010701

[35] Mussolin, C., De Volder, A., Grandin, C., Schlögel, X., Nassogne, M. C., \& Noël, M. P. (2010). Neural correlates of symbolic number comparison in developmental dyscalculia. Journal of cognitive neuroscience, 22(5), http://dx.doi.org/10.1162/jocn.2009.21237

[36] Noël, M. P. (2009). Counting on working memory when learning to count and to add: a preschool study. Developmental Psychology, 45(6), 1630. http://psycnet.apa.org/doi/10.1037/a0016224

[37] Okamoto, Y., \& Case, R. (1996). II. Exploring The Microstructure Of Children's Central Conceptual Structures In The Domain Of Number. Monographs of the Society for Research in Child Development,61(1-2), 27-58. http://dx.doi.org/10.1111/j.15405834.1996.tb00536.x

[38] Passolunghi, M. C., \& Siegel, L. S. (2004). Working memory and access to numerical information in children with disability in mathematics. Journal of Experimental Child Psychology, 88(4), 348-367. http://dx.doi.org/10.1016/j.jecp.2004.04.002

[39] Peard, R. (2010). Dyscalculia: What is its prevalence? Research evidence from case studies. Procedia-Social and Behavioral Sciences, 8, 106-113. http://dx.doi.org/10.1016/j.sbspro.2010.12.015

[40] Piazza, M., Facoetti, A., Trussardi, A. N., Berteletti, I., Conte, S., Lucangeli, D., ... \& Zorzi, M. (2010). Developmental trajectory of number acuity reveals a severe impairment in developmental dy- 
PAPER

\section{ICT BASED SCREENING TOOLS AND ETIOLOGY OF DYSCALCULIA}

scalculia. Cognition, 116(1), 33-41. http://dx.doi.org/10.1016/j.cognition.2010.03.012

[41] Price, G. R., \& Ansari, D. (2013). Dyscalculia: Characteristics, causes, and treatments. Numeracy, 6(1), 2. http://dx.doi.org/10.5038/1936-4660.6.1.2

[42] Reigosa-Crespo, V., Valdés-Sosa, M., Butterworth, B., Estévez, N., Rodríguez, M., Santos, E., ... \& Lage, A. (2012). Basic numerical capacities and prevalence of developmental dyscalculia: The Havana Survey.Developmental Psychology, 48(1), 123. http://psycnet.apa.org/doi/10.1037/a0025356

[43] Rosselli, M., Matute, E., Pinto, N., \& Ardila, A. (2006). Memory abilities in children with subtypes of dyscalculia. Developmental neuropsychology, 30(3), 801-818. http://dx.doi.org/10.1207/s15326942dn3003 3

[44] Rotzer, S., Kucian, K., Martin, E., Von Aster, M., Klaver, P., \& Loenneker, T. (2008). Optimized voxel-based morphometry in children with developmental dyscalculia. Neuroimage, 39(1), 417422. http://dx.doi.org/10.1016/j.neuroimage.2007.08.045

[45] Rubinsten, O. (2009). Co-occurrence of developmental disorders: The case of developmental dyscalculia. Cognitive Development, 24(4), 362-370. http://dx.doi.org/10.1016/j.cogdev.2009.09.008

[46] Rubinsten, O., \& Henik, A. (2005). Automatic activation of internal magnitudes: a study of developmental dyscalculia. Neuropsychology, 19(5), 641-648.http://psycnet.apa.org/doi/10.1037/08944105.19.5.641

[47] Rubinsten, O., \& Henik, A. (2009). Developmental dyscalculia: heterogeneity might not mean different mechanisms. Trends in $\begin{array}{lll}\text { cognitive } & \text { 13(2), } & \text { 92-99. }\end{array}$ http://dx.doi.org/10.1016/j.tics.2008.11.002

[48] Rykhlevskaia E, Uddin LQ, Kondos L and Menon V (2009). Neuroanatomical correlates of developmental dyscalculia: combined evidence from morphometry and tractography. Front. Hum. Neurosci. 3:51. http://dx.doi.org/10.3389/neuro.09.051.2009

[49] Scarpello, G. (2007). Helping Students Get Past Math Anxiety. Techniques: Connecting Education and Careers (J1), 82(6), 34-35.
[50] Shalev, R. S., Manor, O., Kerem, B., Ayali, M., Badichi, N., Friedlander, Y., \& Gross-Tsur, V. (2001). Developmental dyscalculia is a familial learning disability. Journal of learning disabilities, 34(1), 59-65. http://dx.doi.org/10.1177/002221940103400105

[51] Swanson, H. L., \& Beebe-Frankenberger, M. (2004). The relationship between working memory and mathematical problem solving in children at risk and not at risk for serious math difficulties. Journal of Educational Psychology,96(3), 471. http://psycnet.apa.org/doi/10.1037/0022-0663.96.3.471

[52] Szucs, D., Devine, A., Soltesz, F., Nobes, A., \& Gabriel, F. (2013). Developmental dyscalculia is related to visuo-spatial memory and inhibition impairment. Cortex, 49(10), 2674-2688. http://dx.doi.org/10.1016/j.cortex.2013.06.007

[53] Willburger, E., Fussenegger, B., Moll, K., Wood, G., \& Landerl, K. (2008). Naming speed in dyslexia and dyscalculia. Learning and Individual Differences, 18(2), 224-236. http://dx.doi.org/10.1016/j.lindif.2008.01.003

[54] Woodard, T. (2004). The Effects of Math Anxiety on PostSecondary Developmental Students as Related to Achievement, Gender, and Age. Inquiry,9(1), n1.

[55] Wu, S. S., Willcutt, E. G., Escovar, E., \& Menon, V. (2014). Mathematics Achievement and Anxiety and Their Relation to Internalizing and Externalizing Behaviors. Journal of learning disabilities, 47(6), 503-514. http://dx.doi.org/10.1177/0022219412473154

[56] Zimmermann, P., Gondan, M., \& Fimm, B. (2002). KITAP: Testbatterie zur Aufmerksamkeitsprüfung für Kinder. [Test battery for assessing attention in children.]. Herzogenrath: Psytest.

\section{AUTHORS}

Marios A. Pappas and Athanasios S. Drigas are NCSR DEMOKRITOS, Institute of Informatics and Telecommunications, Net Media Lab, Athens, Greece.

Submitted 15 May 2015. Published as resubmitted by the authors 25 June 2015 